\title{
Research on Evaluation System of Green Residential Buildings in Cold Areas of Sichuan
}

\author{
Bin Cheng1, Cong Liu \\ ${ }^{1}$ School of Civil Engineering and Architecture, Southwest University of Science and Technology, Mianyang, China \\ ${ }^{2} \mathrm{CMCU}$ Engineering Corporation, Chongqing, China \\ Email: chengbin@swsut.edu.cn, 1055130047@qq.com
}

How to cite this paper: Cheng, B. and Liu, C. (2020) Research on Evaluation System of Green Residential Buildings in Cold Areas of Sichuan. Journal of Building Construction and Planning Research, 8, 93-118. https://doi.org/10.4236/jbcpr.2020.82007

Received: February 13, 2020

Accepted: May 3, 2020

Published: May 6, 2020

Copyright (c) 2020 by author(s) and Scientific Research Publishing Inc. This work is licensed under the Creative Commons Attribution International License (CC BY 4.0). http://creativecommons.org/licenses/by/4.0/ (c) (i) Open Access

\begin{abstract}
With regard to the rapid growth of China's building area and the increasing energy consumption of buildings, green buildings have become an important issue for balancing economic development and environmental impact. However, the current evaluation systems for various types of green buildings are often unable to achieve a set of standards in practice due to the distinct regional characteristics of each region. Therefore, in view of the regional characteristics of the climate, terrain, ecology, and economic development in the cold regions of Sichuan, it is important to study the evaluation system of green residential buildings suitable for the cold regions of Sichuan. This article focuses on the regional characteristics of climate, topography, ecology, and economic development in the cold regions of Sichuan, and discusses the limitations of the current standards on the practice of green building in cold regions of Sichuan through a sociological questionnaire survey on the comfort of living in the local population. Then from the two dimensions of the advantages of traditional houses and the particularity of national culture, the strategies for the optimization and improvement of the evaluation index system for green residential buildings in the cold regions of Sichuan were proposed. After comprehensively considering the factors that affect the green residential buildings, including the regional characteristics of the cold regions of Sichuan, and the green performance of buildings, local characteristics and ethnic features were included in the evaluation system. The evaluation index system of green residential buildings in the cold regions of Sichuan, consists of 92 three-level indicators. A professional hierarchical analysis software yaahp was used to establish a multi-level hierarchical model between the indicators, and the indicators were compared with each other layer by layer to clarify the importance of the indicators. Based on this, a judgment matrix for each layer was constructed and obtained. The weight of each indicator is accurate, and the scoring mechanism and grading standards are constructed according to it.
\end{abstract}


Through the calculation, the consistency test of the entire model was passed, thereby confirming the scientificity and rationality of the entire evaluation system.

\section{Keywords}

Green Building Evaluation System, Gold Area, Context, Local Standards of Sichuan Province, Residential Building

\section{Introduction}

\subsection{Research History}

In the middle and late part of the last century, the concept of green building has been slowly developed in developed countries. Subsequently, under the impetus of social development and economic improvement, the green building evaluation system has also ushered in relatively rapid development and application as a supporting technology. For green buildings, 1990 was an important starting point. The British Building Research Establishment first proposed the BREEAM (Building Research Establishment Environmental Assessment Method), a complete evaluation system specifically for green buildings. This evaluation system has officially become the world's green A landmark event in architectural development [1]. Driven by BREEAM's nascent system, the evaluation of building performance began to attract the attention of experts and scholars and related practitioners in the field of architecture in more and more countries. In the late 1990s, it was also an important landmark. The United States issued the LEED (Leadership in Energy \& Environmental Design Building Rating System) [2] [3] [4]. Around the same time, GBTool, which was jointly developed by many countries, was officially launched [5] [6]. These internationally influential evaluation systems have emerged, enriching the number and type of green building and green building evaluation systems. After the $21^{\text {st }}$ century, the concept of green building is fully developed. More countries and regions are promoting green building concepts and developing and implementing relevant green technologies. The evaluation system of green buildings has also begun to form its own complete system in various regions and regions with their respective regional characteristics as important influencing factors. For example, Japan's CASBEE system, Australia's NABERS system, etc., these systems strongly promote the recognition and popularization of green building concepts around the world [7] [8].

These evaluation systems continuously absorb experience, summarize problems, and then carry out deeper improvements and revisions in practice. Just take the US LEED evaluation system as an example: the LEED system has proposed the new building evaluation system LEED-NC, the existing building evaluation system LEED-EB, the building core tube and shell evaluation system 
LEED-CS, for the commercial building interior. The design evaluation system LEED-CI, LEED-SCHOOL, which is specific to the school building evaluation system, and the LEED-H system, which is specifically designed for the home building, can be used to evaluate each type of building [9] [10] [11] [12].

Green building evaluation systems such as BREEAM and LEED have gradually expanded the applicable building categories of their evaluation systems with the continuous development of green building concepts and technological advancement. From the beginning, it only expanded to the new office buildings and commercial buildings, and gradually expanded to the current comprehensive system covering education, medical, industrial and other fields. Moreover, these mature systems are scientific and practical operability. It has been gradually promoted and popularized in different countries and regions around the world, and has formed a tremendous global influence. For example, the global green building project that has been officially certified by BREEAM has reached an astonishing 2.27 million buildings; the LEED-certified construction projects have also expanded to 165 countries and regions around the world [13] [14] [15].

China's green building research started relatively late, but from the development of green building related research and practice in these years, first of all, the core concept of green building has received considerable attention from government agencies, research institutes and academia. It further promoted the building's transition from the characteristics of high resource consumption of the status quo to the green ecology.

In September 2001, China launched the "China Ecological Housing Technology Assessment Manual" (first edition), which greatly promoted research in related fields, and applied the accumulated related technologies in practice, and made quite a few value exploration. In 2003, due to the need to prepare for the next Olympic Games, China conducted in-depth research on the Olympic buildings and their ancillary buildings in advance. Here, the concept of green building has been fully introduced, and a specifically targeted "Green Olympic Building Evaluation System" has been launched [16]. In June 2006, in order to speed up the development of green buildings and make the green building standards have the framework and universality of the whole country, China issued the "Green Building Evaluation Standards" (GB/T 50378-2006) [17]. The emergence of this standard has a milestone significance for the development of green buildings in China. Its framework is complete and comprehensive, and it is also the first domestic custom green building evaluation standard to evaluate residential and public buildings. Subsequent green building standards are based on the basic framework of the standard, and are expanded for different building types and fields. With more evaluation standards for various building types and local standards in various provinces and cities, China's green buildings have ushered in a diversified development period of architectural type and geographical adaptability. 


\subsection{Research Questions}

Although green buildings are blooming and fruiting all over the country, and relevant regional studies have been in full swing, due to China's vast size and diverse climate, provinces and cities, and even different regions within the same province, their resource richness. There are obvious differences in regional culture, economic level and environmental carrying capacity, so this difference has become an important driving force for the formation of local green building evaluation standards. Most parts of China, especially in the western part of China, are still relatively backward and poor due to various objective factors. Such a complicated and special status quo puts forward higher and more specific requirements for the construction of green building evaluation system and the design practice of green building: it must fully consider the geographical characteristics of each region and the green and ecological properties of the building. Forming an important impact, and based on the overall satisfaction of the green building and ecological framework, research and explore different areas and different architectural forms, adopting different design strategies and ecological technologies suitable for the local natural environment. The essence of the green renewal of regional architecture is to emphasize the various natural, human and economic factors of regional architecture in the environment, and to achieve a high degree of coordination in combination with green technology. Coordinating these influencing factors is also crucial to the green building evaluation system. If it is not in the green building evaluation system, and effective restraint and guidance on regional factors, it is easy to cause green buildings to appear in unsuitable places. It is incompatible with the environment, or causes various problems such as indifference, loss of national culture, and single architectural features.

This article refers to the "Sichuan Province Residential Building Energy Efficiency Design Standards" (DB51-5027-2012) released in 2012. According to the number of heating days and air conditioning days, combined with the geographical characteristics, climate characteristics, monthly average temperature and other indicators of Sichuan Province, Sichuan will be The province is divided into four climate zones: severe cold, cold, hot summer, cold winter and mild regions.

The zoning indicator for cold regions is $3800>$ HDD18 $>2000$, which mainly includes Malcom City, Kangding City, Batang County, Xinlong County, Xiaojin County, Daofu County, Wenchuan County, Mao County, Li County, Jiulong County, and Danba. Some areas, such as the county, have the climatic characteristics of "cold winter, cool summer". The climate zoning map of Sichuan Province is shown in Figure 1.

\subsection{Research Innovation}

1) Cultural sustainability

The current green building evaluation standard emphasizes the green performance of the building, but considering the current situation of multi-ethnic 


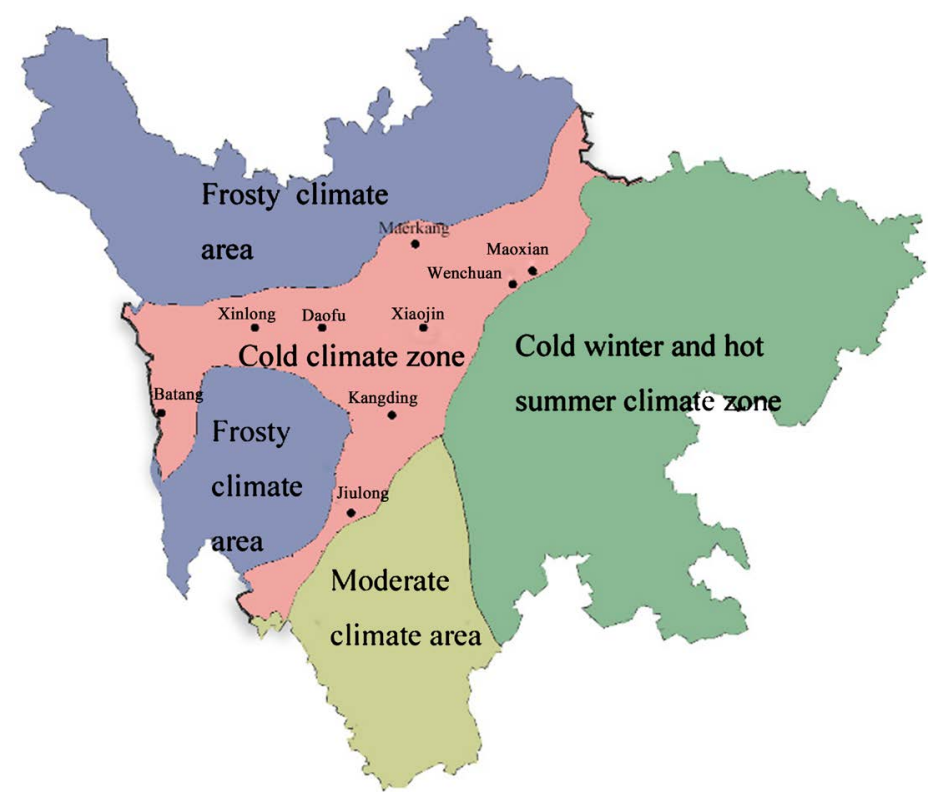

Figure 1. Building climate division map of Sichuan Province.

settlement in the cold regions of Sichuan, the religious beliefs and national culture of all ethnic groups, even if they meet the Green Building practice of the standard, if they do not do well in religion. The green transformation of beliefs and national culture cannot be recognized by local residents, and residents are reluctant to live in such buildings. The standard will lose its meaning of guiding the green renewal of regional buildings. This paper hopes to incorporate cultural sustainability into the indicators of the green building evaluation system, combining green buildings with regional culture.

2) Geographic suitability

The cold regions of Sichuan have their own particularities in terms of climate, topography, ecology, and social economy. Based on the targeted analysis of the cold regions of Sichuan, this paper proposes a green building evaluation system specifically for the region, which can fully reflect the geographical suitability of the green building evaluation system in the cold regions of Sichuan.

\section{Methodology}

\subsection{Establish a Multi-Level Evaluation Model}

The hierarchical model in this paper refers to the typical AHP hierarchy. The model is divided into four levels. The target layer is green building, and the lower two layers are 8 first-level indicators and 25 second-level indicators. The final solution layer has 92 options. The structural relationship is shown in Figure 2. The model can be simply expressed as: target layer $A=\left\{B_{1}, B_{2}, B_{3}, \cdots, B_{N}\right\}$, criteria layer $B=\left\{C_{i 1}, C_{i 2}, C_{i 3}, \cdots, C_{i N}\right\}$, specific indicators $\mathrm{C}$.

\subsection{Structural Judgment Matrix}

In the hierarchical model that has been constructed, we compare each level of 
indicators with other indicators at the same level to determine the impact of that indicator is more clear and more important, avoiding subjective selection of indicators. The resulting difference in the conclusions of the various evaluators is then based on the degree of importance of this quantification to construct a judgment matrix. $U=\left\{u_{1}, u_{2}, u_{i}, \cdots, u_{n}\right\}$. In the formula, $u_{i} \in U,(i=1,2, \cdots, N)$. To clarify how much influence weight of one indicator in the whole criterion layer, then we should compare this indicator with each indicator under the same criterion layer in turn, and then determine the importance of the indicator in the whole criterion layer. $U_{i j}$ indicates that the importance of element $i$ and element $j$ is almost equal, $A=\left(\mathrm{u}_{i j}\right) \cdot n \cdot n$ Use this to represent the judgment matrix constructed.

$$
A=\left(U i_{j}\right) n \times n=\left[\begin{array}{cccc}
u_{11} & u_{12} & \cdots \cdots & u_{1 n} \\
u_{21} & u_{22} & \cdots \cdots & u_{2 n} \\
\cdots & \cdots & \cdots & \cdots \\
u_{n 1} & u_{n 2} & \cdots \cdots & u_{n n}
\end{array}\right]
$$

The results of the comparison of the indicators in the same layer of the criteria layer, we quantify them, get 9 scales, through the description of these scales, let us clarify the importance of its individual indicators relative to the other. The scale of importance is shown in Table 1.

\subsection{Consistency Test}

Calculate $\lambda=\frac{1}{n} \sum_{i=1}^{n} \frac{(A w)_{i}}{w_{i}}$; Find an approximation of the largest eigenvalue.

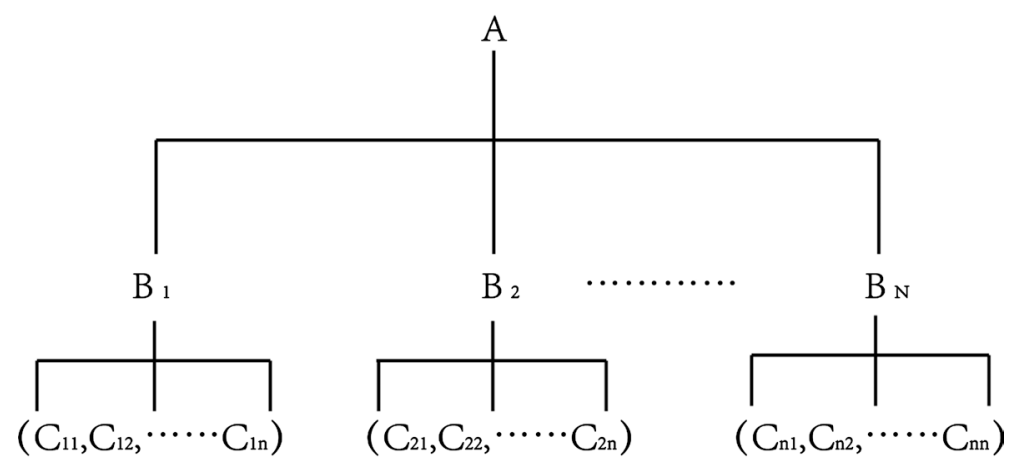

Figure 2. Multi-level evaluation model established in this paper.

Table 1. Classification of importance.

\begin{tabular}{cl}
\hline Scaling & meaning \\
\hline 1 & Expressing the same importance compared to two factors. \\
3 & Compared with the two factors, the former is slightly more important than the latter. \\
5 & Compared with the two factors, the former is obviously more important than the latter. \\
7 & Compared with the two factors, the former is much more important than the latter. \\
9 & Compared with the two factors, the former is extremely more important than the latter. \\
$2,4,6,8$ Indicates the intermediate value of the above adjacent judgment.
\end{tabular}




$$
A w=\left[\begin{array}{cccc}
a_{11} & a_{12} & \ldots & a_{1 n} \\
a_{21} & a_{22} & \ldots & a_{2 n} \\
\ldots & \ldots & \ldots & \ldots \\
a_{n 1} & a_{n 2} & \ldots & a_{n n}
\end{array}\right]\left[\begin{array}{c}
w_{1} \\
w_{2} \\
\ldots \\
w_{3}
\end{array}\right]=a_{i 1} w_{1}+a_{i 2} w_{2}+\cdots+a_{i n} w_{n}
$$

Whether the model can pass a consistent test requires a judgment of a specific value. The test formula is: $C R=C I / R I$. When $C R<0.1$, the model is able to pass the consistency test. When $C R>0.1$, the model does not meet the consistency test, and needs to be adjusted accordingly to make the value meet the requirements.

\section{Analysis of Characteristics of Local Traditional Dwellings}

The research in this paper has benefited from the team's repeated penetrations into Aba Prefecture and Ganzi Prefecture, and has obtained a wealth of research results, including real-life photos of local traditional houses and related data on building physical environment testing. The research provides a strong foundational support.

\subsection{Architectural Planning Site Selection}

In this paper, a typical climatic region is selected for Danba County, Sichuan Province. Danba County is located in the high mountainous area of the Lushan Mountain Range. There are countless mountain valleys in the territory, forming a unique terrain with peaks and peaks. The highest altitude in Danba County is 5820 meters, and the lowest point is 1700 meters. The terrain is very obvious. Suopo Township is located between the mountain and the valley, with a maximum elevation of 4570 meters and a minimum elevation of 1.78 meters. Typical topographic models of Suopo Township are shown in Figure 3 and Figure 4.

Under such terrain and geomorphology, the slope land is extremely rare, and most of the land resources are composed of slopes and terraces on the slopes. Therefore, the main living environment and scenes of the Jiarong Tibetans are also built on slopes and terraces. Moreover, since the generations of Jiarong Tibetans, farming has been the main production and life style. Although there are also livestock and poultry, the people of the Jiarong Tibetans rely heavily on land cultivation and have a deep and strong feeling for the land. They built the house on slopes that are not suitable for cultivation. For the Jiarong Tibetans, cultivated land can be said to be an extremely valuable resource, and no piece of land should be wasted without meaning. Therefore, in the process of site selection, in order to further save farmland, local residents often choose some slopes and terraces that are difficult to achieve. And from this investigation, it can be clearly seen that the Jiarong Tibetan dwellings in Suopo Township are often built on the mountain. Moreover, due to the special environment of the hillside, it is impossible to construct in a piecewise manner, so the local architectural combination and the courtyard form all show a typical scattered layout. The settlement pattern of the alpine gorge in this area is shown in Figure 5, and the residential buildings are shown in Figure 6. 


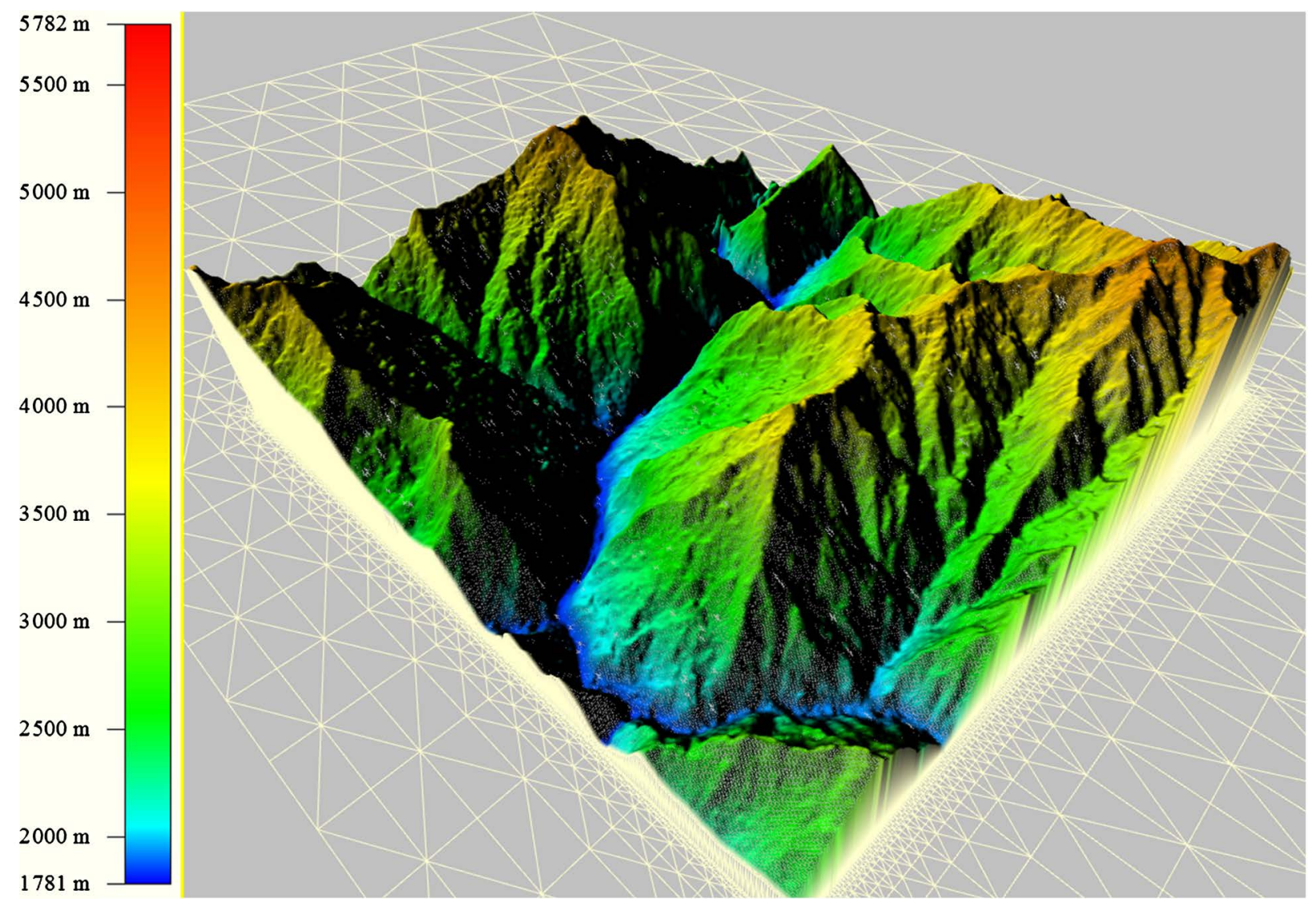

Figure 3. Suopo Township terrain model 1.

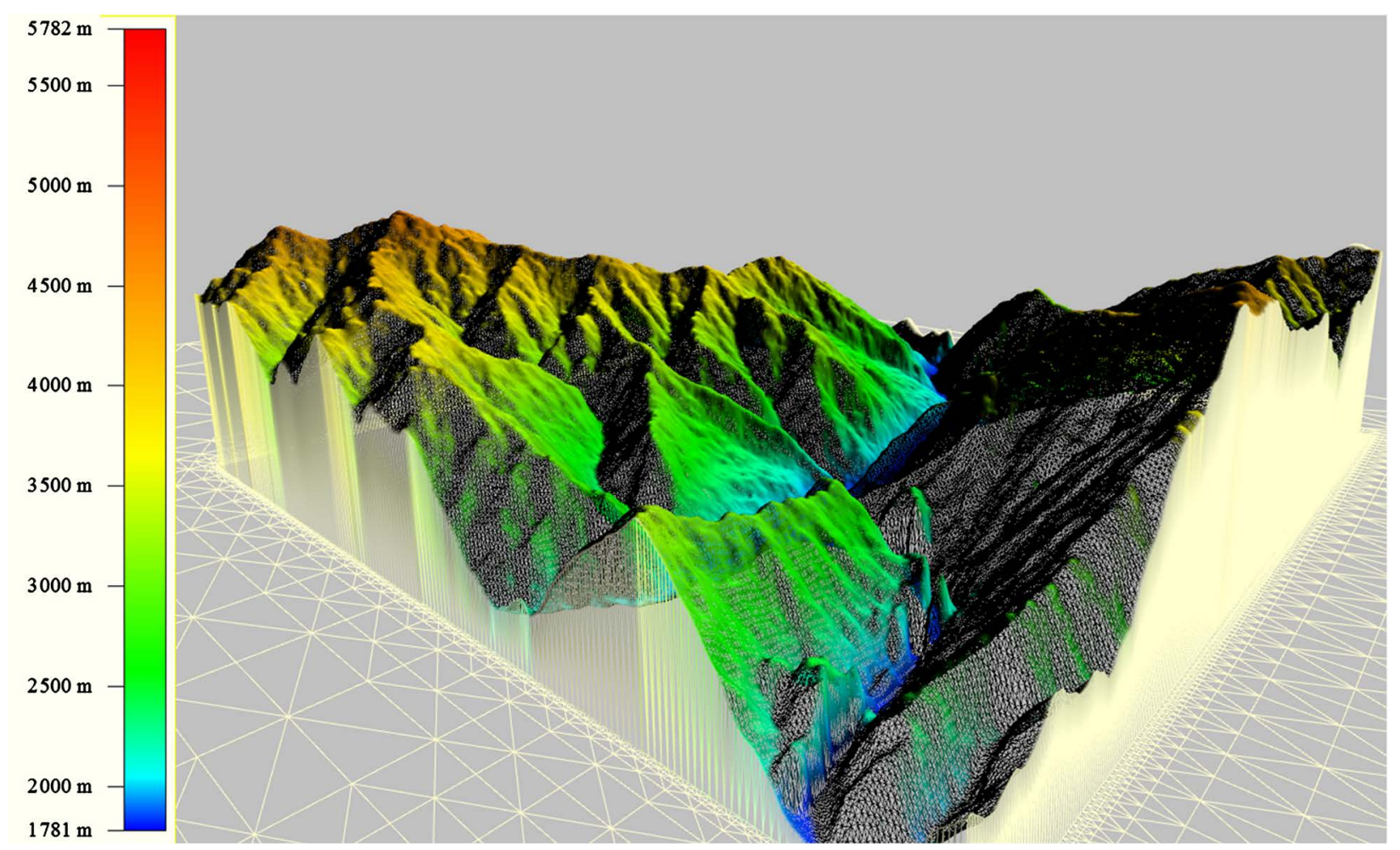

Figure 4. Suopo Township terrain model 2. 


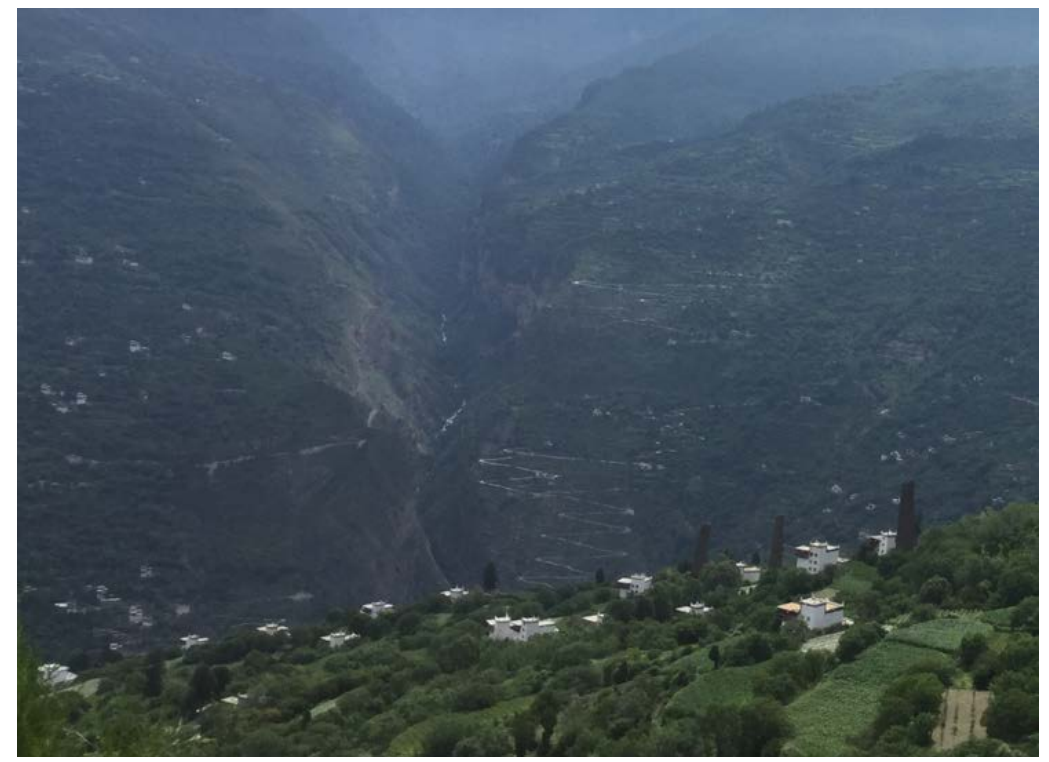

Figure 5. Settlement layout of Suopo Township.

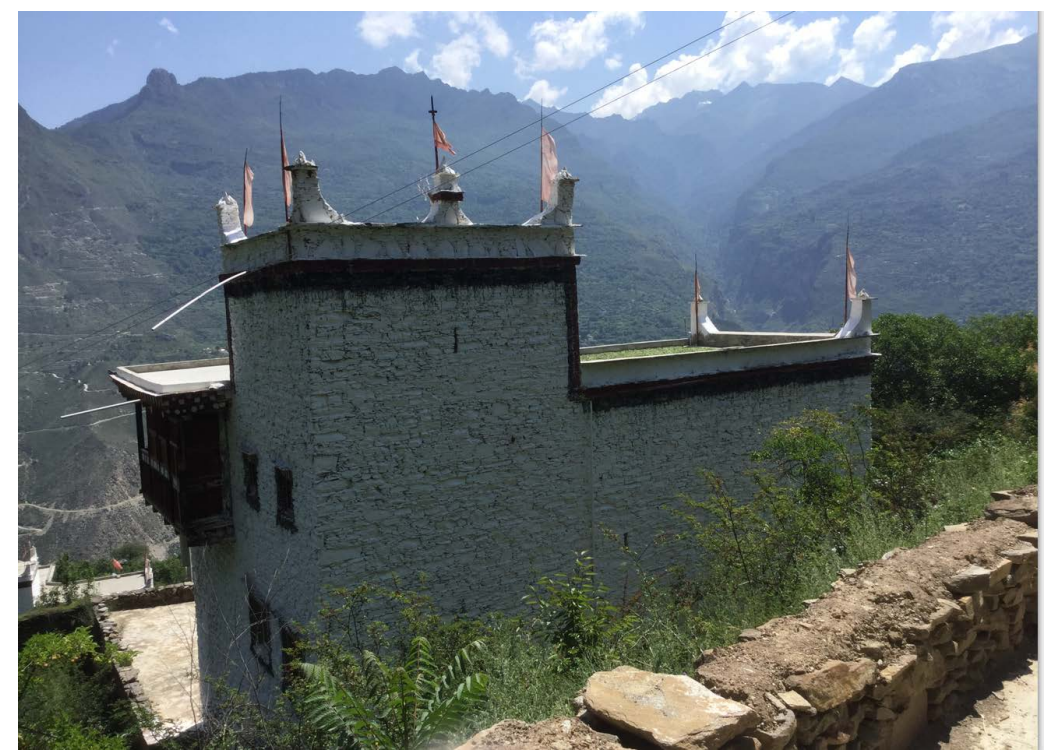

Figure 6. Suojia typical residential style.

In summary, local residents in Suopo Township pay great attention to the conservation and utilization of land resources when they are constructing sites, and have developed rich experience and unique technologies for the development and utilization of slopes and terraces. The experience of building these traditional houses is also in line with the requirements of the green building concept. The deep feelings of the local residents and the needs and experience of the development and utilization of the slope land should be taken into account in the process of constructing the green evaluation indicators.

\subsection{Building Materials}

The walls of the villages in Suopo Township are all made of locally produced stone, 
which is a typical stone house. The exterior walls of some buildings are painted white, but some buildings still retain the color of the walls themselves. Although they are both stone-built buildings, the villages of Suopo Township are quite different from the traditional stone buildings in the West. The stone used is often small stones that are bare on the surface, rather than huge stones that are as complete as Western architecture. These small-sized stones, through the unique methods of Tibetan residents, fill the mud between the stones to form a stable and thick wall. Because of its own location in the mountains, the town of Suopo is very rich in resources and very easy to obtain. And because the stone itself comes from the neighborhood of the residents' life, it will not have a negative impact on the nearby ecological environment during the entire life cycle of the building, even after the building is completely abandoned. The stone itself comes from nature and finally returns to nature, which is the goal pursued by green buildings. The detailed performance of the stone texture exterior wall in traditional houses is shown in Figures 7-10.

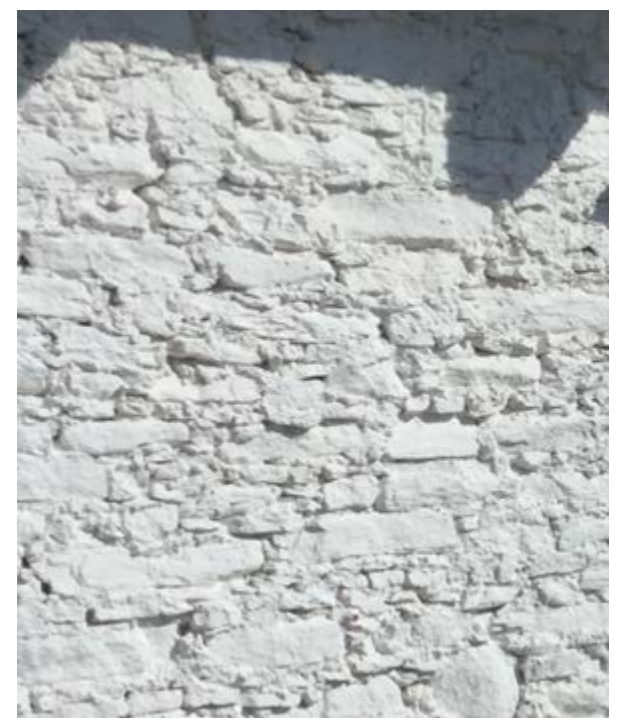

Figure 7. Residential stone wall 1.

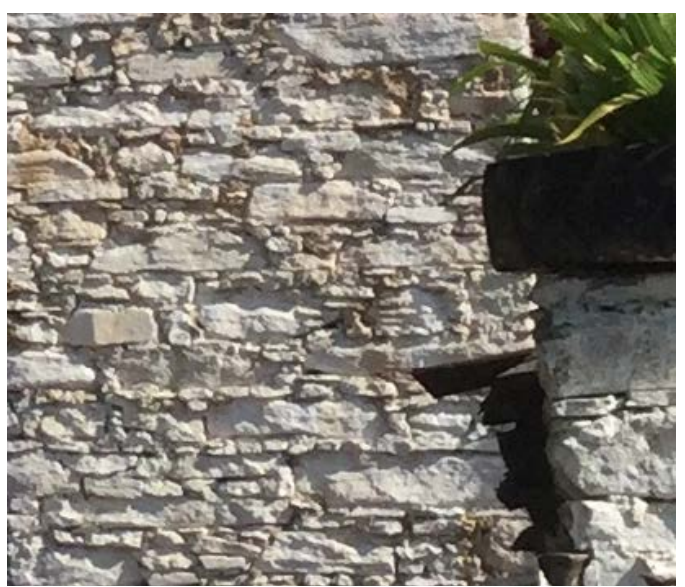

Figure 8. Residential stone wall 2. 


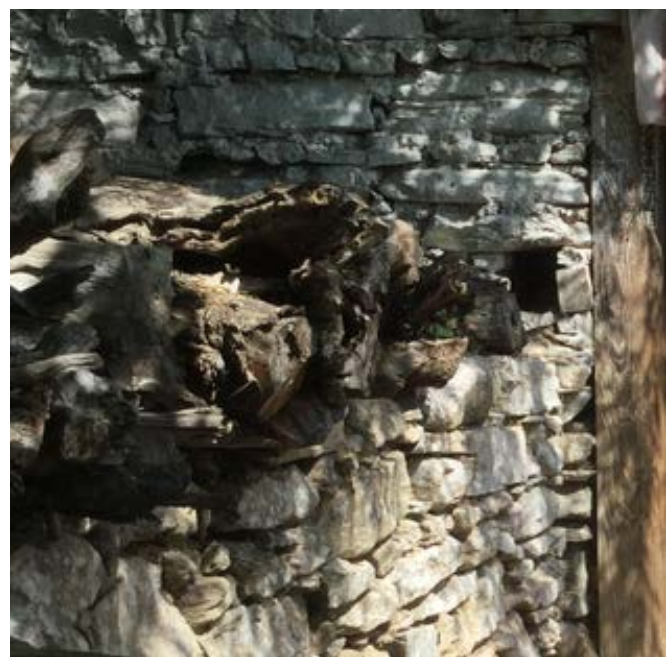

Figure 9. Residential stone wall 3.

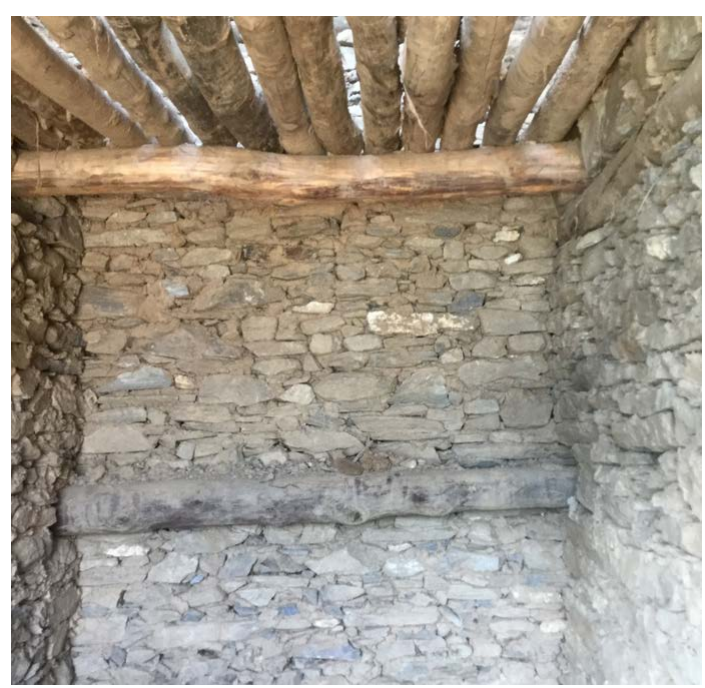

Figure 10. Residential stone wall 4.

\subsection{Building Facade}

The Tibetan dwellings in Suopo Township have distinctive features and rich shapes. Since the site selection of the buildings is mostly slopes and terraces, the building itself has also formed a layer of retreat, which is perfectly integrated with the outdoor environment. This not only meets the needs of the building's functions in space, but also creates a pleasant visual effect. Looking at it, the building conforms to the topography, and the platform is retired and beautiful. In terms of architectural color, the Jiarong Tibetan dwellings in Suopo Township and the Tibetan dwellings in other areas have strong consistency. They all like to use bright red, black and yellow. The color of the building is very rich and the personality is very clear. The color of the wall is mainly white, and some houses are made of warm yellow primary color of stone. The wooden components are mostly painted red or preserved in wood color, and most of the window covers are painted black. The mouth of the daughter's wall is often decorated with yel- 
low and red, forming a very bright embellishment. The color paintings on the doors and windows are more colorful and very beautiful. The details of the facade of the regional building and its decoration are shown in Figures 11-14.

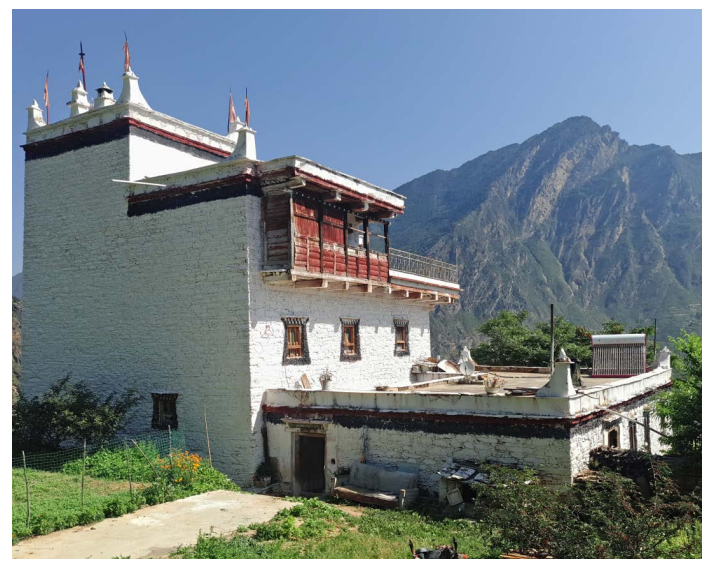

Figure 11. Residential façade features.

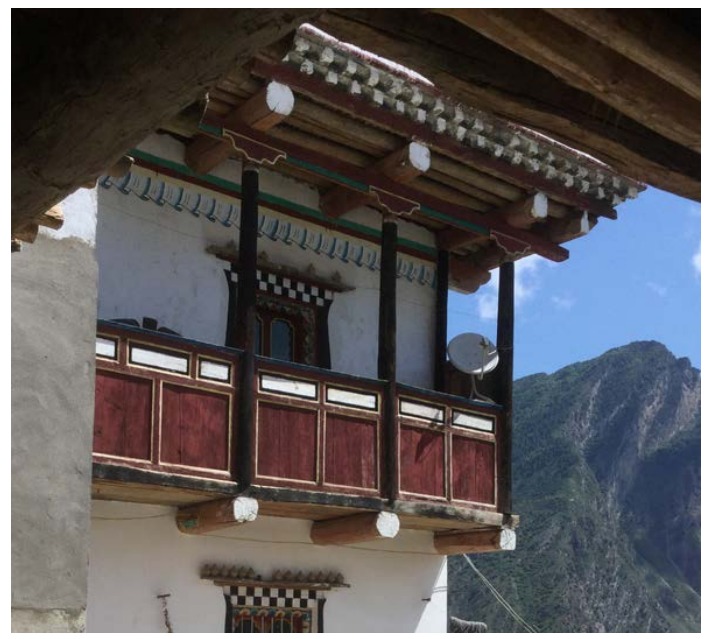

Figure 12. Residential building.

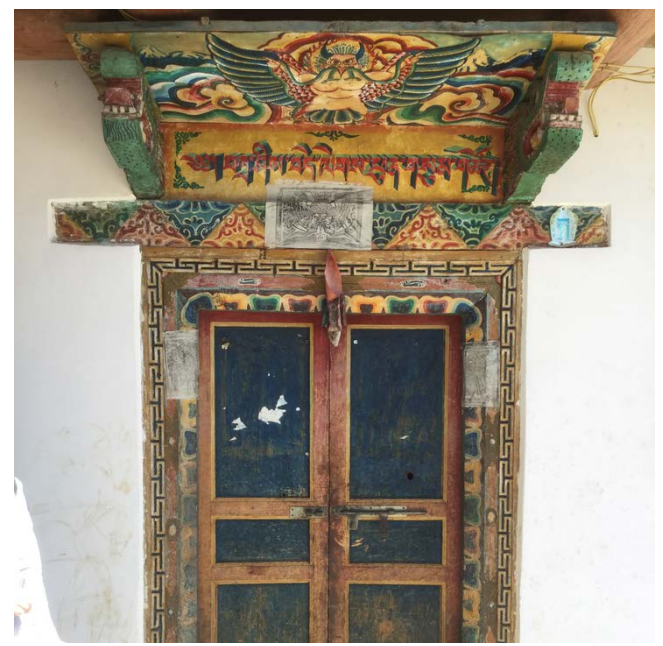

Figure 13. Folk door decoration. 


\subsection{Indoor Hot and Humid Environment}

The team of the research team conducted a test of the indoor thermal and humid environment in the residential area of Suopo Township. The continuous uninterrupted test data was selected from March 10 to 11, 2016 (the test results are shown in Figure 15), and continuous testing from September 7 to September 8, (the test results are shown in Figure 16).

In terms of temperature, it can be seen that the outdoor environment in Suopo

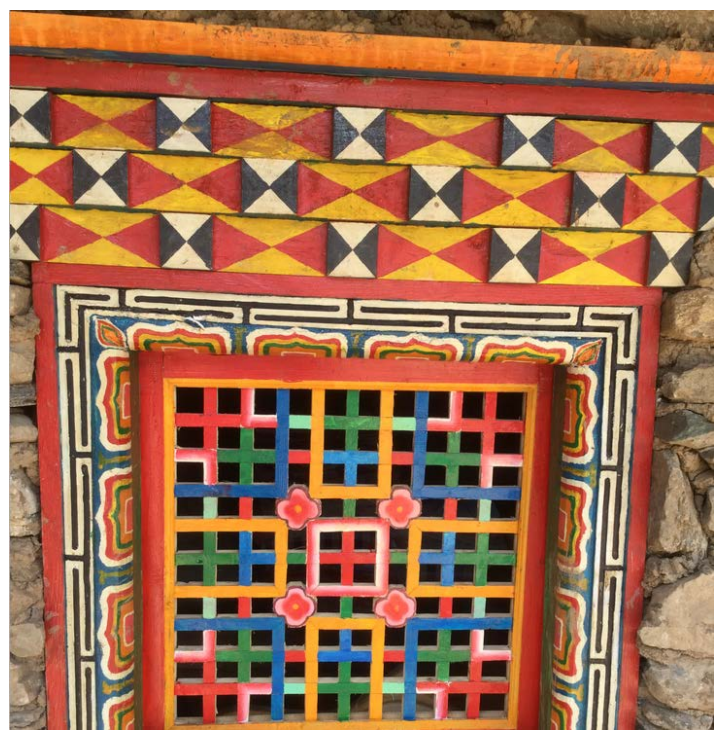

Figure 14. Exterior window decoration.

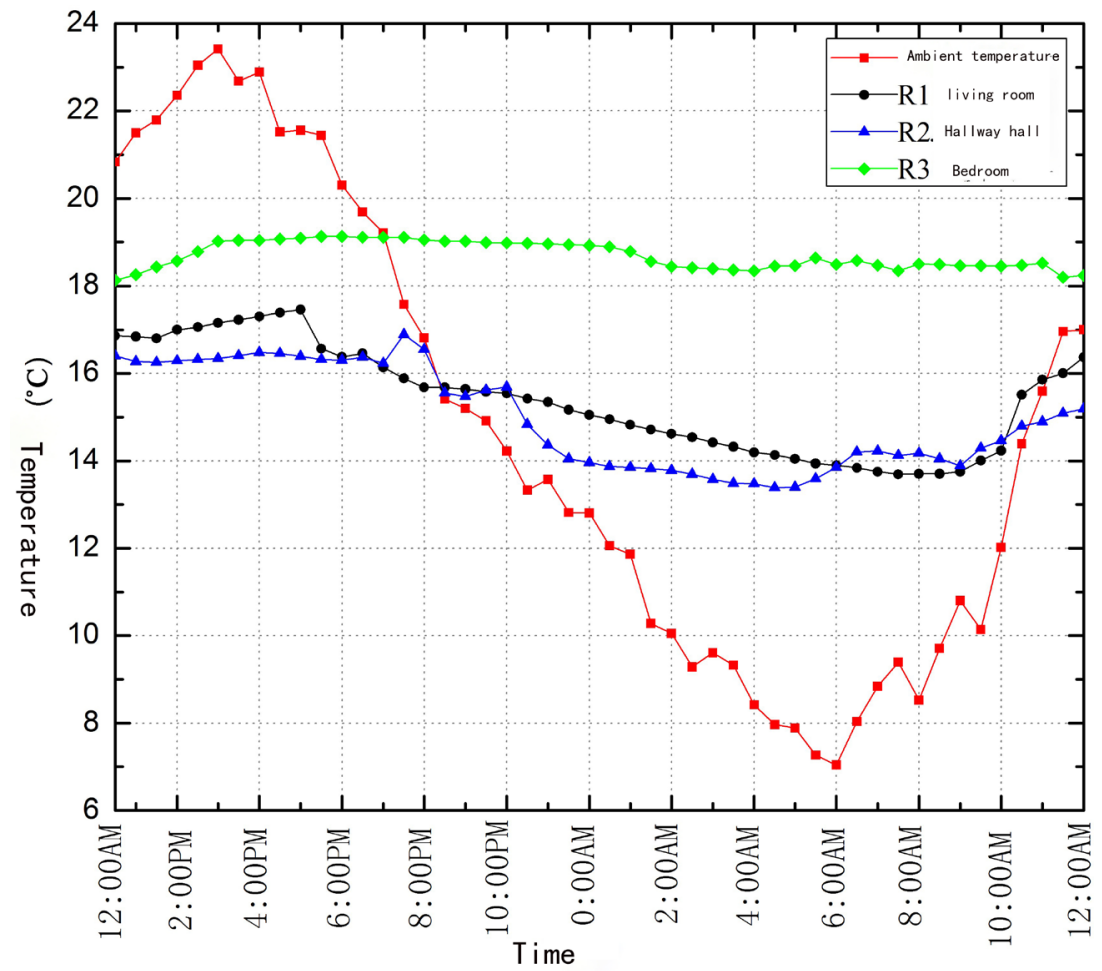

Figure 15. Temperature change in March. 


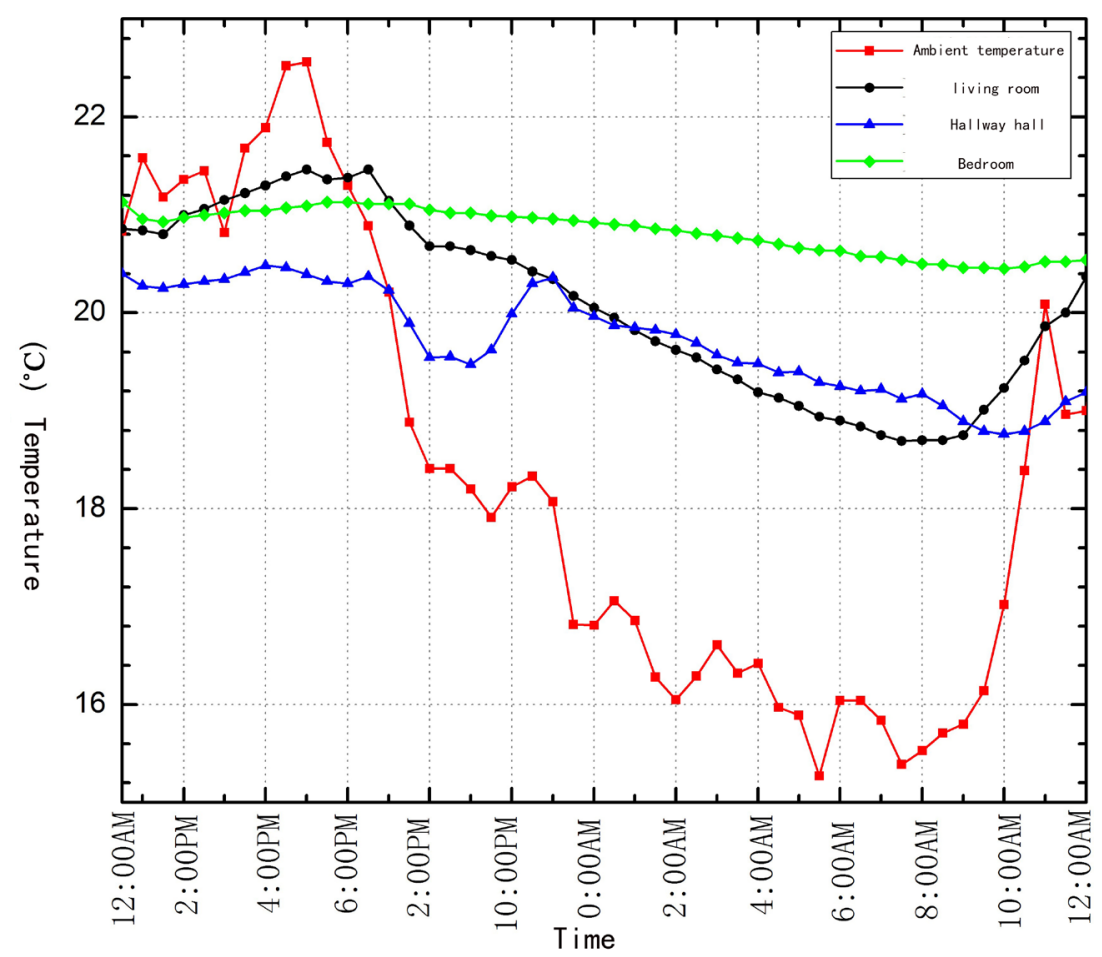

Figure 16. Temperature change in September.

Township is very obvious in spring and autumn. The data on March 10 indicates that the maximum temperature of the outdoor environment has reached $23.3^{\circ} \mathrm{C}$, but the lowest temperature can be reduced to $6.8^{\circ} \mathrm{C}$; the data on September 7 is $22.8^{\circ} \mathrm{C}$ is the highest temperature of the outdoor environment of the day; $14.8^{\circ} \mathrm{C}$ is the lowest temperature of the outdoor environment of the day. The temperature difference between the two tests reached $16.5^{\circ} \mathrm{C}$ and reached $8^{\circ} \mathrm{C}$. In such an area where the outdoor ambient temperature changes so drastically, the temperature of each room will fluctuate to varying degrees with time. By comparing the temperature data of the living room on the first floor, the living room on the first floor and the bedroom on the second floor, we found that the temperature on the first floor and the first floor had a certain degree of fluctuation with time, but the overall change was not large. It is $4^{\circ} \mathrm{C}$. The temperature fluctuations in the bedroom on the second floor were extremely stable and the fluctuation range did not exceed $1^{\circ} \mathrm{C}$. This shows that the local Jiarong Tibetan dwellings have very good thermal insulation properties, and in contrast, the building thermal environment on the second floor bedroom is superior to the living room and the living hall on the first floor.

In terms of humidity, the humidity difference in the outdoor environment of Suopo Township is very obvious in spring and autumn. According to the data of March 10 (The test results are shown in Figure 17), the outdoor environmental humidity in the area varies between $42.7 \%$ and $83 \%$, and the fluctuation range is very large, reaching $40 \%$; and the outdoor environmental humidity on September 7 is $57.4 \% \sim 64 \%$ (the test results are shown in Figure 18). The change between 


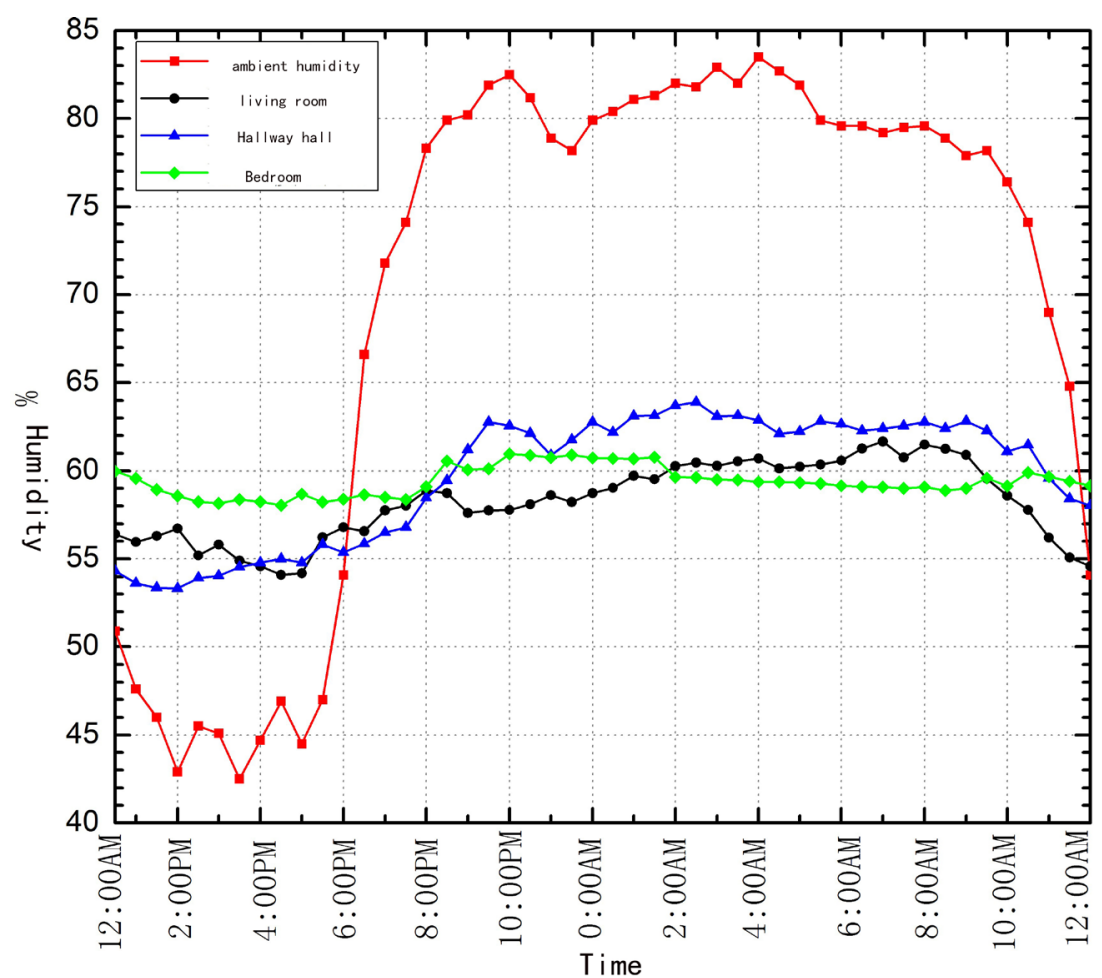

Figure 17. Indoor humidity change 1.

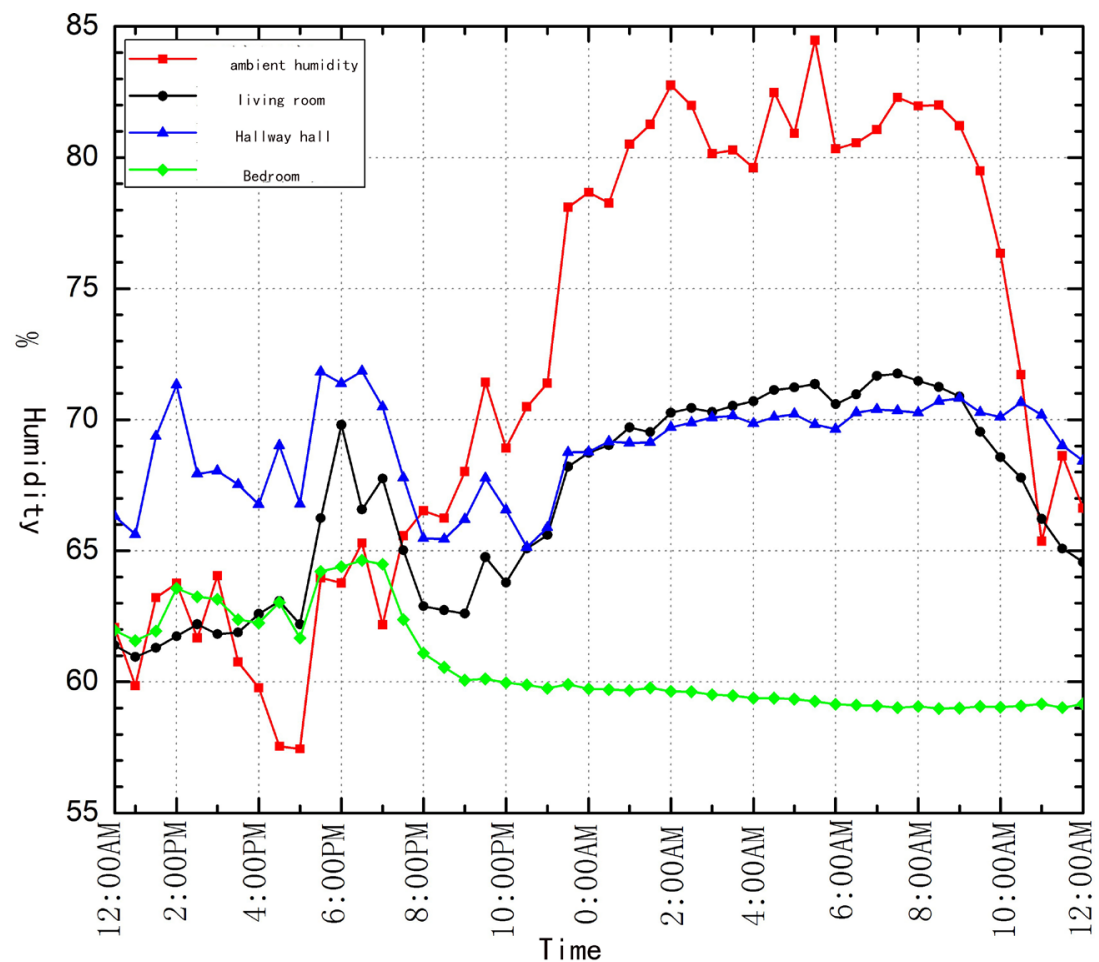

Figure 18. Indoor humidity change 2 .

$84.5 \%$, although the fluctuation range only reached $28 \%$, but only at night, the outdoor environment humidity has exceeded $70 \%$, and this humidity has been maintained for a very long time. For the internal space of the test dwelling, the 
living room and the hall on the first floor were basically maintained at a relative humidity of $53 \%$ to $64 \%$ on March 10 , while the bedroom on the second floor was maintained at the indoor humidity during the test of the day between 57\% and $61 \%$. In general, the humidity on the first floor of the first floor and the living room on March 10 was within $11 \%$, while the second-floor bedroom was more stable, with a variation of less than $4 \%$. In the test on September 7 , the relative humidity of the living room and the living room on the first floor varied from $60 \%$ to $72 \%$, while the relative humidity of the air in the bedroom on the second floor varied from $59 \%$ to $64 \%$. In general, on September 7 th, the humidity in the living room and the living room changed by less than $12 \%$, and the change in the bedroom on the second floor was within $5 \%$. Such data fully reflects the excellent moisture barrier performance of the test dwellings, and the wet environment of the second floor bedroom is superior to the first floor hall and living room.

Indoor temperature and humidity have a very significant impact on human health and human comfort. In the outdoor environment of Suopo Township, the temperature difference between day and night is large, and the humidity difference is also very large. In such weather, people are particularly vulnerable to colds and other diseases. However, the internal environment of the local dwellings maintains a very stable temperature and humidity, which is very important for the health and comfort of the residents. These advantages of traditional local dwellings deserve our reference and reference.

\section{Questionnaire and Analysis}

\subsection{Resident Questionnaire}

The author team conducted a questionnaire survey of residents in the cold regions of Sichuan. A total of 50 questionnaires were sent out and 47 valid questionnaires were returned. According to the results of this survey, this paper sorts out the importance of residents in the cold regions of Sichuan for the importance of green building-related evaluation indicators. The survey results are shown in Figure 19.

In the survey statistics on the importance of green building evaluation indicators for local residents, local residents can be more concerned about the secondary indicators such as water-saving appliances and equipment, building materials selection, environmental protection, resource conservation, and environmental management. A higher score is obtained, and the secondary indicators such as energy comprehensive utilization, non-traditional water source utilization, indoor light environment and field of view, and process management are less concerned and give lower scores. In the process of constructing the weights of green building evaluation indicators in cold regions of Sichuan, the actual needs and opinions of local residents should be taken into consideration, and the weights of secondary indicators such as water-saving appliances and equipment, material selection, environmental protection, resource conservation, and environmental management should be increased. The local residents are very concerned 


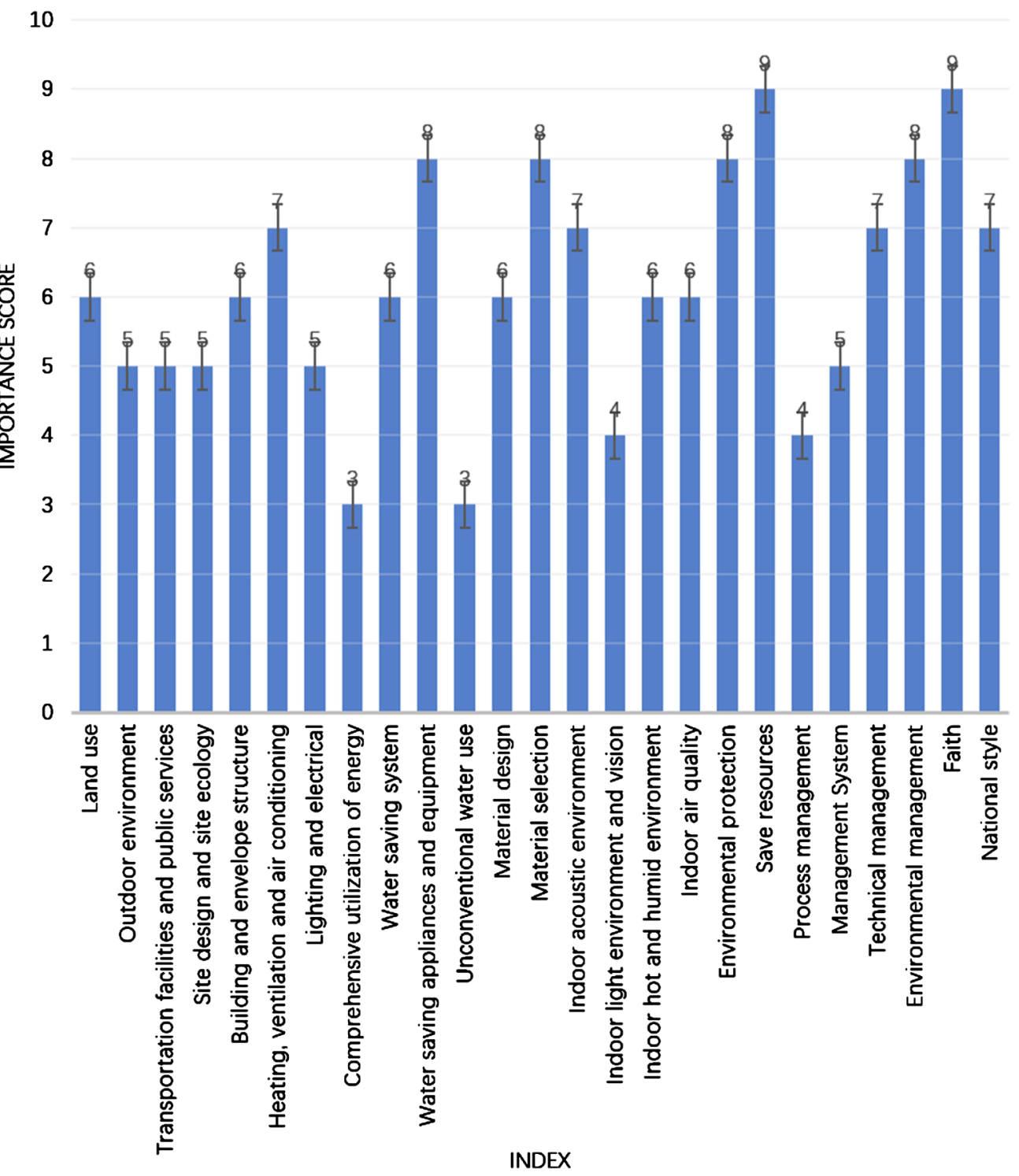

Figure 19. Index importance score.

about the indicators of humanistic sustainability. They give a very high weight of 9 points for the secondary indicator of religious belief, and a higher weight of 7 points for the national style.

\subsection{Optimization of the Indicator System}

In the practice of green building, the eyes are more devoted to the local residents' adaptation to production methods, the pursuit of life, and the satisfaction of spiritual beliefs. The green building thus formed can be widely accepted by local residents in order to better deal with the complex relationship between architecture and people, architecture and the environment.

In the process of formulating a new green building evaluation system in cold regions of Sichuan, national characteristics and style should be included as a first-level indicator in the indicator system, including secondary indicators such as religious 
beliefs and national customs, architectural decoration, architectural color, architectural shape, Three levels of indicators such as interior space design.

After the new evaluation index is added, the first-level evaluation index becomes eight, and the weight statistics of the eight first-level indicators are shown in Figure 20.

The first level indicator is national characteristics and features. There are two secondary indicators, and their weight ratios are shown in Figure 21. The second primary indicator is land saving and outdoor environment. There are four secondary indicators, and their weight ratios are shown in Figure 22. The third level indicator is Energy saving and energy utilization, of which there are four level

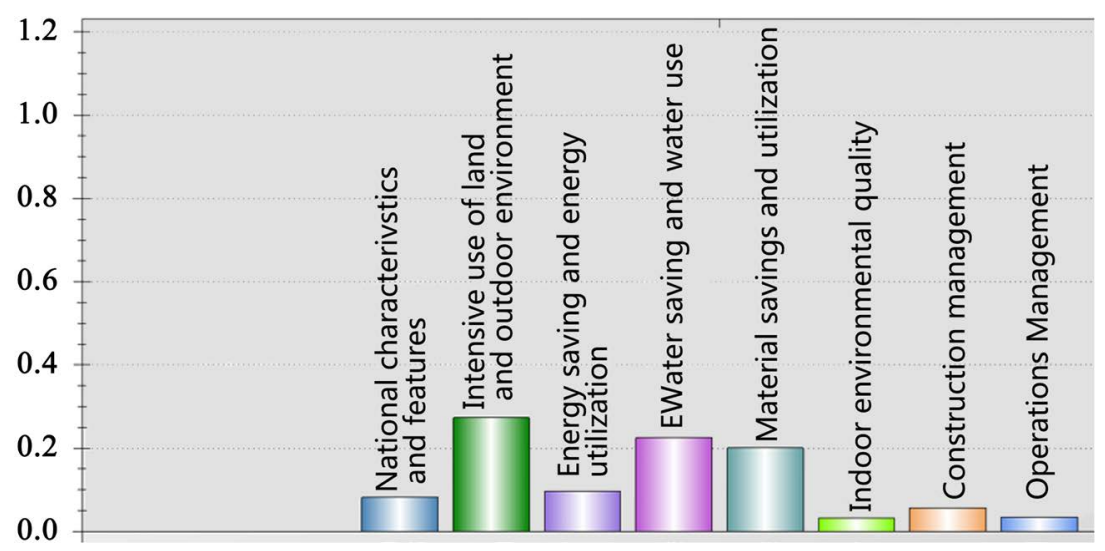

Figure 20. The weight of secondary indicators in the primary system.

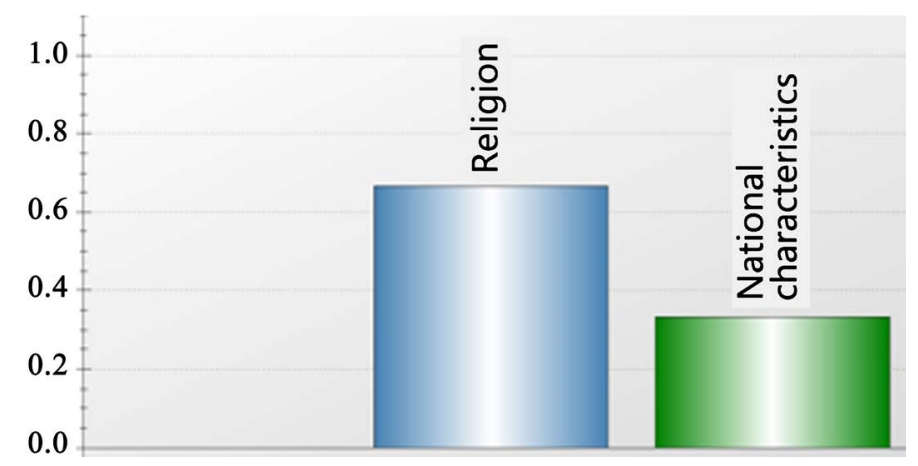

Figure 21. National characteristics and features.

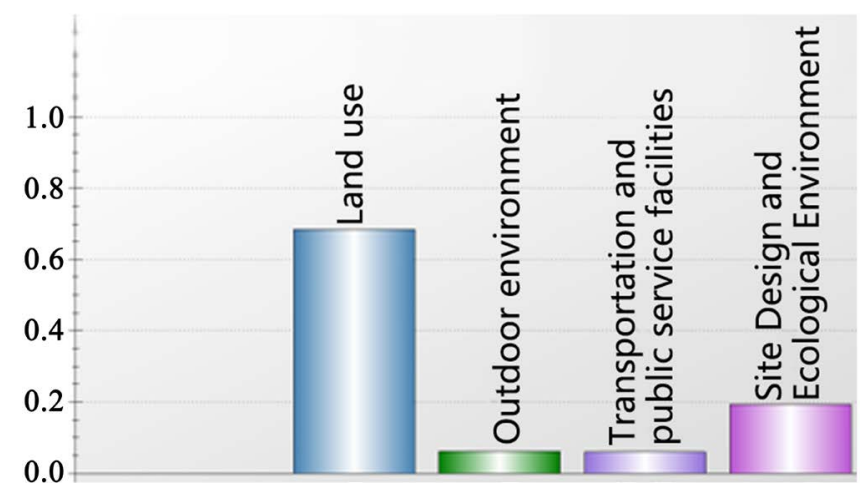

Figure 22. Land saving and outdoor environment. 


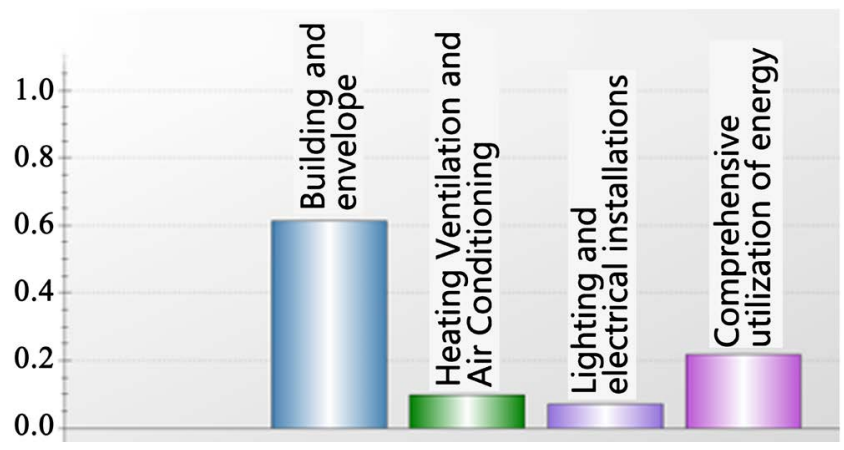

Figure 23. Energy saving and energy utilization.

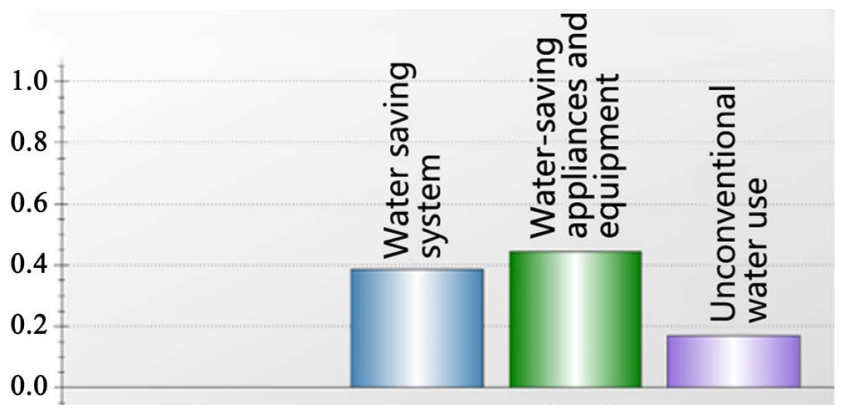

Figure 24. Water saving and water use.

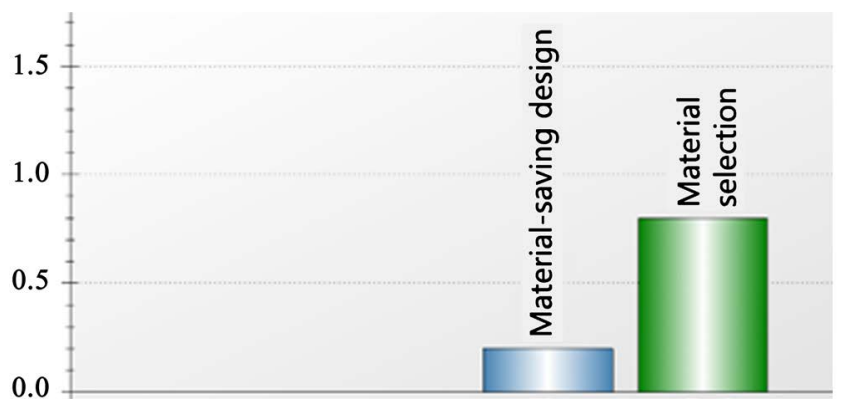

Figure 25. Material saving and material resource utilization.

two indicators, and their weight ratios are shown in Figure 23; The fourth level indicator is water conservation and water resource utilization. There are three level two indicators, and their weight ratios are shown in Figure 24.

The fifth level indicator is material saving and material utilization. There are two level indicators and their weight ratios are shown in Figure 25. The sixth primary indicator is the indoor environmental quality. There are four secondary indicators, and their weight ratios are shown in Figure 26. The seventh level 1 indicator is construction management, of which there are three level 2 indicators. The eighth level indicator is operational management, of which there are three level two indicators, and their weight ratios are shown in Figure 27. Technical management is slightly more important than the management system, and technical management is slightly more important than the environmental management. Environmental management is equally important compared to the system management system. Its weight ratio is shown in Figure 28. 


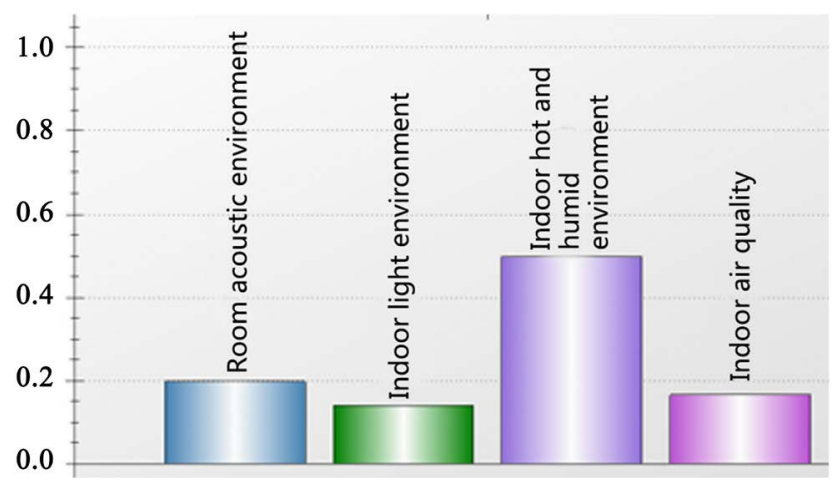

Figure 26. Indoor environmental quality.

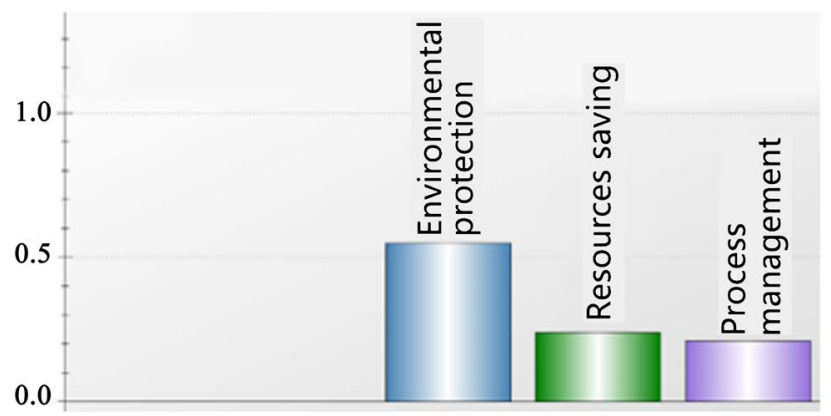

Figure 27. Construction management.

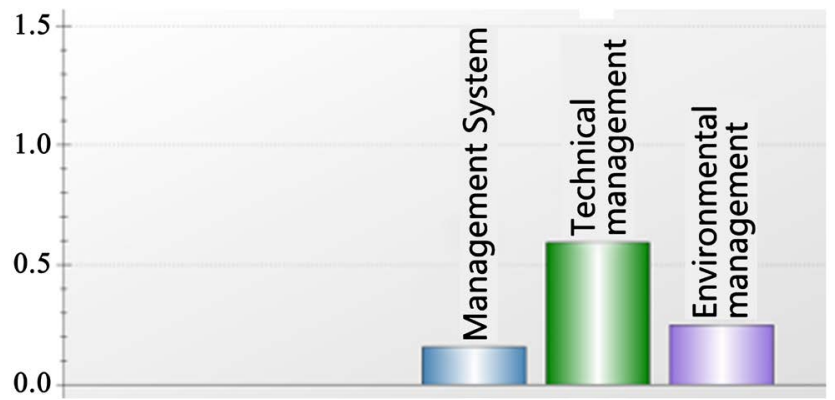

Figure 28. Operations Management.

\section{Construction of Evaluation System}

\subsection{Construction of Indicator System}

Since there are 8 first-level indicators, 25 second-level indicators, and 92 third-level indicators. If the number of indicators is so large, the professional computing software yaahp using AHP analytic method will make subsequent calculations. It's simpler and can reduce calculation errors. This article uses yaahp software to build a complete model covering all the metrics that need to be studied in this paper, and automatically perform subsequent calculations using software. Its model structure system is shown in Figure 29.

\subsection{Construction of Judgment Matrix}

The construction of the judgment matrix is mainly through the expert to compare each indicator, and then quantify its importance, and give a clear data scale 
from 1 to 9.

Regional green residential building evaluation system, its first level of judgment matrix, see Figure 30. It can be seen from the figure that in the eight categories of

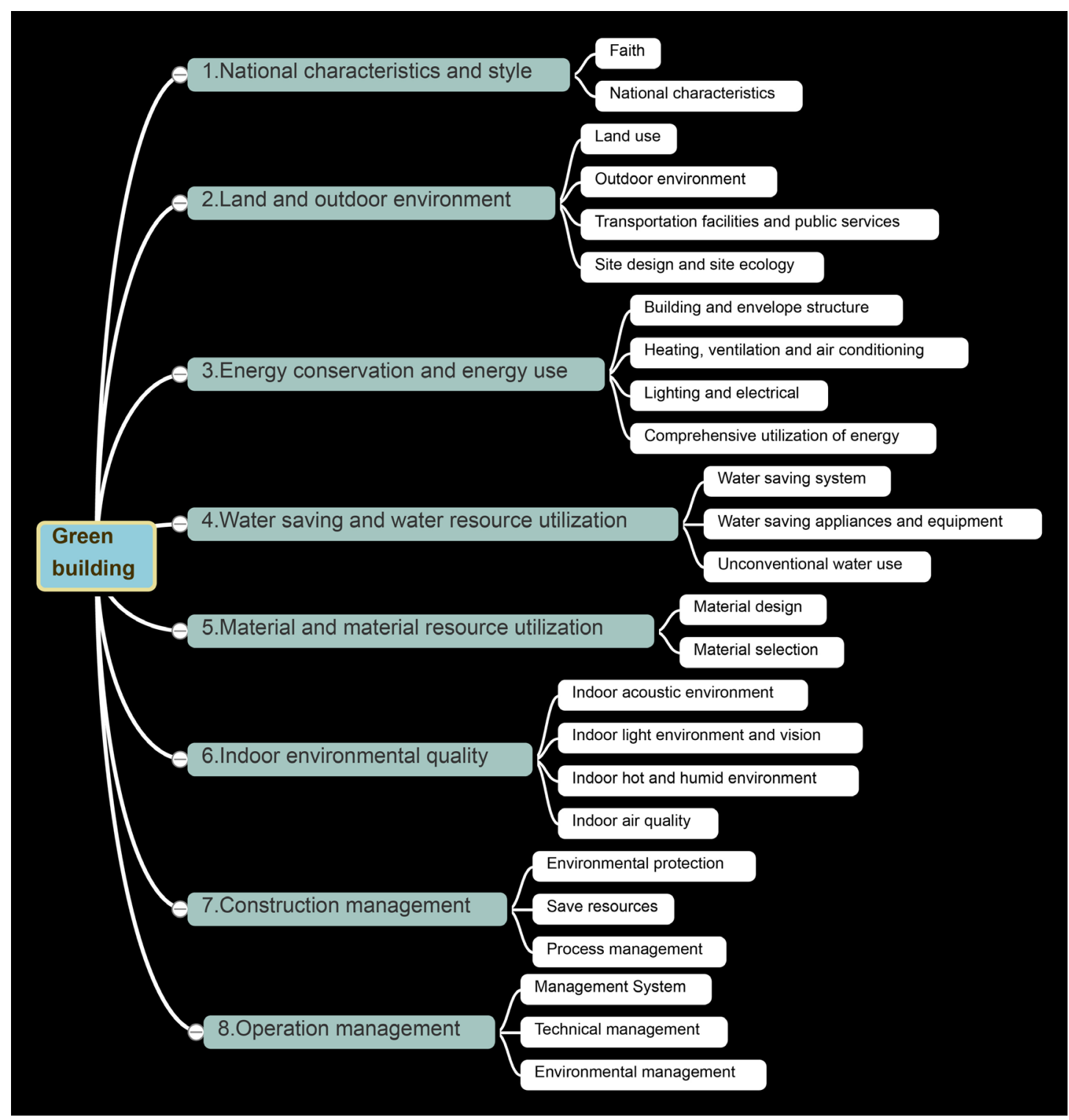

Figure 29. Hierarchical model of the paper.

\begin{tabular}{|c|c|c|c|c|c|c|c|c|}
\hline & $\begin{array}{l}\text { National } \\
\text { characteris } \\
\text { tics and } \\
\text { style }\end{array}$ & $\begin{array}{l}\text { Land and } \\
\text { outdoor } \\
\text { envirorme } \\
\text { nt }\end{array}$ & $\begin{array}{l}\text { Energy } \\
\text { conservatio } \\
\mathrm{n} \text { and } \\
\text { anergy use }\end{array}$ & $\begin{array}{l}\text { Water } \\
\text { saving and } \\
\text { water } \\
\text { utilization }\end{array}$ & $\begin{array}{l}\text { Material } \\
\text { and } \\
\text { matrial } \\
\text { utilization }\end{array}$ & $\begin{array}{l}\text { Indoor } \\
\text { envirorme } \\
\text { nt }\end{array}$ & $\begin{array}{l}\text { Constructi } \\
\text { on } \\
\text { managem } \\
\text { ent }\end{array}$ & $\begin{array}{l}\text { Operation } \\
\text { manageme } \\
\text { nt }\end{array}$ \\
\hline National characteristics and style & & $1 / 4$ & $1 / 2$ & $1 / 3$ & $1 / 3$ & 4 & 3 & 2 \\
\hline Land and outdoor envirorment & & & 5 & 2 & 2 & 8 & 2 & 4 \\
\hline Energy conservation and anergy use & & & & $1 / 3$ & $1 / 4$ & 2 & 4 & 5 \\
\hline Water saving and water utilization & & & & & 2 & 4 & 5 & 6 \\
\hline Material and matrial utilization & & & & & & 4 & 6 & 6 \\
\hline Indoor envirorment & & & & & & & $1 / 3$ & $1 / 2$ \\
\hline Construction management & & & & & & & & 4 \\
\hline Operation management & & & & & & & & \\
\hline
\end{tabular}

Figure 30. Judgment matrix. 
first-level indicators, the land-saving and outdoor environment is the most important category of green residential buildings in the cold regions of Sichuan, water conservation and water resources utilization, material utilization and material resource utilization. Energy conservation and energy utilization are second. According to this method, we can also construct its second-level and third-level structural construction models and calculate the importance of different elements.

\subsection{Calculation of Index Weights}

By performing detailed calculations with Yaahp software, it is possible to calculate the weight value of each indicator under the model established in this paper, which can finally be integrated into a weight table, which is the weight of the green residential building evaluation system in the cold regions of Sichuan. See Table 2. The table lists the different indicator layers and their weight values in the indicators at all levels.

\subsection{Consistency Test}

By using yaahp software, through the consistency check of the index level model, the target layer $\mathrm{CR}=0.0982<0.1$ was calculated. The combination consistency ratio of the first-level indicators is: 0.0662 , which also passed the consistency test; the combination consistency ratio of the second-level indicators: 0.0683 , which also passed the consistency test.

\section{Conclusions and Discussion}

\subsection{Discussion}

Incorporating regional technology and national culture into the evaluation index system of green residential buildings in the cold regions of Sichuan can accelerate the development of green buildings, but we must also see that there are three issues that need to be further studied. First, regional green buildings standards, although the evaluation system has increased the proportion of local materials and regional practices, but the scientific nature of this proportion needs to be further demonstrated, especially the research population has limitations and the number of experts is also limited. Secondly, it is also necessary to consider whether the two secondary indicators of religious culture and ethnic characteristics are set in the primary indicators of ethnic characteristics and features. For low-cost green buildings, the appropriate regional technology is also an important evaluation indicator, similar to India's Barker. Richina Dorsey's works are excellent, but they are also low-tech regional green buildings. Third, there are three-level indicators under the first-level indicators of national characteristics and features. Some of the three-level indicators have problems with the three-level indicators of other items. How to divide these elements is also an aspect to be considered. 
Table 2. Weights of indicators at all levels.

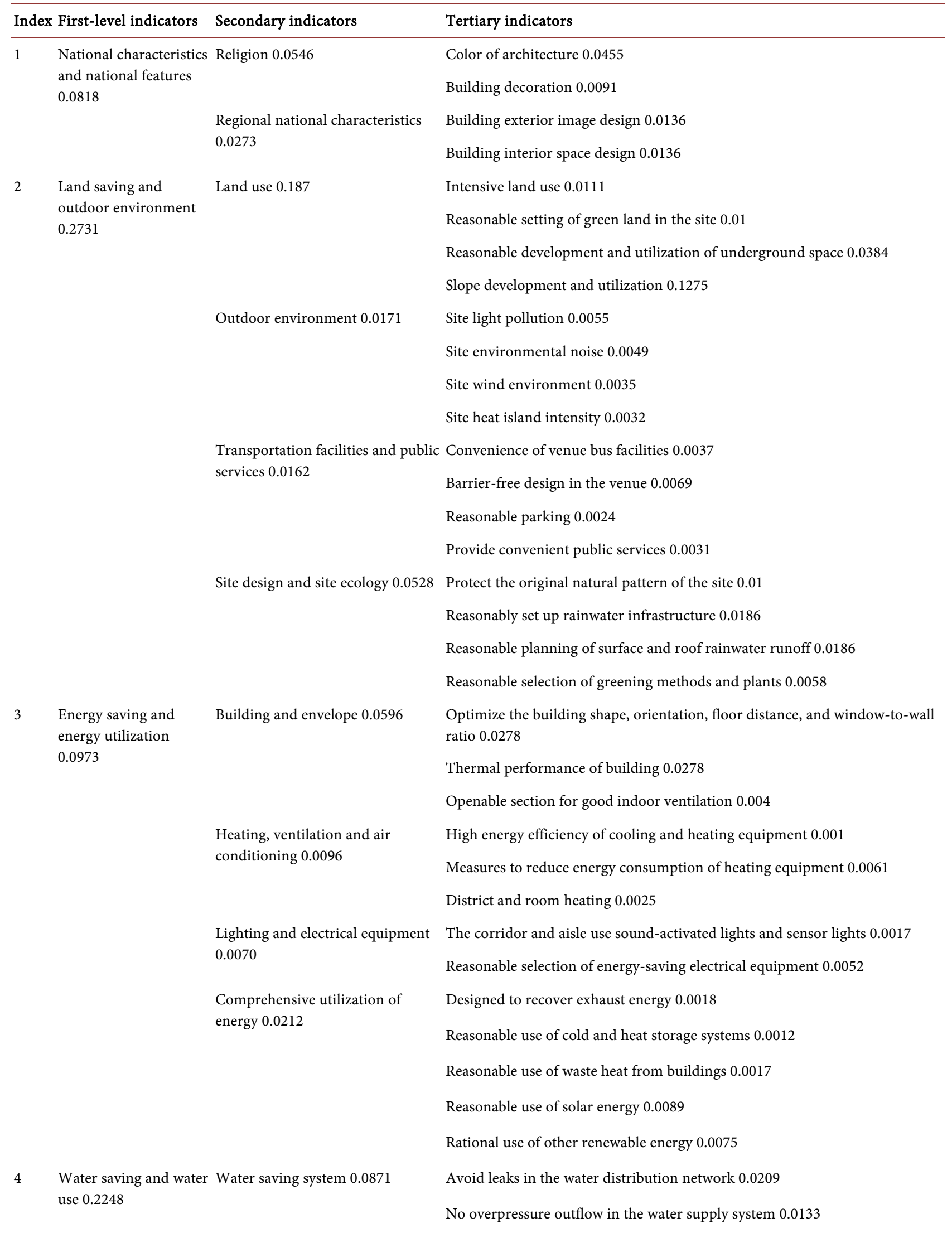




\section{Continued}

Install water metering device 0.0075

Public bathrooms take water-saving measures 0.0454

Water-saving appliances and equipment 0.0997

Unconventional water use 0.038

Material-saving design 0.0410 material utilization 0.2005
Indoor environmental quality 0.0316 0.0062

Material selection 0.1604

Indoor acoustic environment

Indoor light environment 0.0044

\section{Indoor hot and humid} environment 0.0157

Indoor air quality 0.0052

Environmental protection 0.0309 management 0.0563
Water efficiency of sanitary appliances 0.0195

Use of water-saving irrigation systems 0.0431

Air-conditioning system adopts water-saving cooling technology 0.0195

Other equipment also uses water-saving technologies or measures 0.0176

Unconventional water use 0.038

Choosing the best building shape 0.0136

Optimize structural design to achieve material saving effect 0.0095 Integrated design of civil engineering and decoration 0.0027

Reusable partition wall 0.0037

Use of industrially produced prefabricated components 0.006

Integrated design kitchen and bathroom space 0.0046

Use ready-mixed concrete and ready-mixed mortar 0.0067

Use of high-strength building structural materials 0.0054

Use of durable construction materials 0.0095

Use of recyclable and recyclable materials 0.0173

Construction materials produced from waste 0.0227

Use durable, easy-to-maintain decoration materials 0.0133

Using thermal insulation and structural integration technology 0.0085

Use locally produced stone as building material 0.077

Noise level in the main room 0.0011

Good sound insulation in main function rooms 0.0028

Adopt measures to reduce noise interference 0.0024

Main room with good view 0.0003

Main function room lighting meets national standards 0.0008

Improve the natural lighting effect in the room by design 0.0011

Adjustable shading design reduces radiation 0.0022

Improve natural ventilation by design 0.0017

Reasonable airflow organization 0.0006

Install devices to regulate and improve indoor air 0.0029

Take dust protection measures during construction 0.0097

Take effective noise reduction measures during construction 0.0038

Reduce waste 0.0136

Take measures to reduce light pollution during construction 0.0038

Develop and implement a construction energy saving plan 0.0054 


\begin{tabular}{|c|c|c|c|}
\hline & & Save resources 0.0135 & $\begin{array}{l}\text { Develop and implement construction water conservation and water use plans } \\
0.0032\end{array}$ \\
\hline & & & Develop and implement construction material saving plan 0.0027 \\
\hline & & & Use tooling stereotypes 0.0023 \\
\hline & & & Strict control of design document changes 0.0046 \\
\hline & & Process management 0.0118 & Take steps to ensure building durability 0.0016 \\
\hline & & & Integrated construction of civil engineering and decoration engineering 0.0033 \\
\hline & & & Joint trial run before completion 0.0023 \\
\hline & & & Certified property management agency 0.0008 \\
\hline 8 & Operations & Management system 0.0054 & Formulate operational rules for energy and water conservation 0.0013 \\
\hline & & & Implementation of energy management incentives 0.0018 \\
\hline & & & Publicity mechanism for green environmental education 0.0009 \\
\hline & & & Cultural environment of residential district 0.0007 \\
\hline & & & Regular inspection of public facilities and equipment 0.004 \\
\hline & & Technical management 0.0206 & Regular inspection and cleaning of air conditioning ventilation system 0.0028 \\
\hline & & & Complete and accurate water quality and usage records 0.0057 \\
\hline & & & Application of information technology for property management 0.008 \\
\hline & & & Use pollution-free pest control technology 0.0009 \\
\hline & & Environmental management & First survival rate of planted and transplanted trees 0.0006 \\
\hline & & 0.0086 & The garbage collection station does not pollute the environment 0.0025 \\
\hline & & & Implement separate waste collection and treatment 0.0045 \\
\hline
\end{tabular}

\subsection{Conclusion}

A local green building evaluation system was established by surveying local social groups and scoring by industry experts. This evaluation system solves the problem of inheritance of regional architectural culture and ethnic architectural characteristics, respects regional religions and ethnic customs, and promotes the promotion of ethnic minority areas in China. The development of green buildings has a good role in promoting the recognition of green buildings in ethnic areas.

\section{Acknowledgements}

This article is funded by the Sichuan Provincial Department of Education's Key Scientific Research Project Fund. Project Name: Research on the Green Building Model and Technical System of the Stone-Built Dwellings in the Western Sichuan Plateau.

\section{Conflicts of Interest}

The authors declare no conflicts of interest regarding the publication of this paper. 


\section{References}

[1] Mulligan, H. and Steemers, K. (2002) Total Energy Use in Refurbishment: Avoiding the over Commitment of Resource. PLEA 2002 Conference Proceedings, 2, 61-67.

[2] Ural, O. (1980) Energy Resources and Conservation Related to Built Environment. Proceeding of the International Conference on Energy Resource and Conservation Related to Built Environment, No. 3, 7-20.

[3] Landsberg, D.R. and Steward, R. (1980) Improving Energy Efficiency in Building. State University of New York Press, New York, 6-12.

[4] Santamouris, M. and Balaras, C.A. (1996) Energy Conservation and Retrofitting in Hellenic Hotels. Energy and Buildings, No. 24, 65-75.

https://doi.org/10.1016/0378-7788(95)00963-9

[5] Thomas, P.C., Natarajan, B. and Anand, S. (1990) Energy Conservation Guidelines for Government Office Building in New Delhi. Energy and Buildings, No. 2, 617-623. https://doi.org/10.1016/0378-7788(91)90030-7

[6] Lambert, S. and Parker, G. (2009) The Green Ratings War-Winning Strategies. Building and Construction Law Journal, No. 25, 179-187.

[7] Huang, Q.Y. (2005) Research on the Evaluation of Domestic Green Buildings. Master Thesis, Sichuan University, Chengdu.

[8] Qiao, Y.F. (2006) Analysis and Evaluation of Energy Consumption of Traditional Dwellings Based on LCA. Xi'an University of Architecture and Technology, Xi'an, 5-6.

[9] Henry Gifford's Lawsuit against U.S. Green Building Council Dismissed. http://www.lexology.com/library/detail.aspx?g=20d3439d-c5fe-4e31-a16c-e915c61b $\underline{\mathrm{d} 674}$

[10] Heijungs, R., Guinée, J.B., Huppes, G., et al. (1992) Environmental Life Cycle Assessment of Products: Guide and Backgrounds (Part 2).

[11] de Haes, U. (1996) Towards a Methodology for Life Cycle Impact Assessment. Society of Environmental Toxicology and Chemistry.

[12] Guinée, J.B., Heijungs, R., Oers, L., et al. (1996) LCA Impact Assessment of Toxic Releases. Generic Modelling of Fate, Exposure and Effect for Ecosystems and $\mathrm{Hu}-$ man Beings with Data for about 100 Chemicals.

[13] Bare, J.C. (2002) Developing a Consistent Decision-Making Framework by Using the US EPA's TRACI. AIChE, Indianapolis, IN.

[14] Gloria, T.P., Lippiatt, B.C. and Cooper, J. (2007) Life Cycle Impact Assessment Weights to Support Environmentally Preferable Purchasing in the United States. Environmental Science \& Technology, 41, 7551-7557. https://doi.org/10.1021/es070750+

[15] Abaza, M. (2012) High Performance Buildings Using Whole Building Integrated Design Approach. Strategic Planning for Energy and the Environment, 31, 19-34. https://doi.org/10.1080/10485236.2012.10491661

[16] Dian, J. (2002) "Restriction of Hazardous Substances in Interior Decoration" 10 Mandatory National Standards Issued. Quality Supervision and Consumption, No. $1,9$.

[17] Tian, H.F., Zhang, H., Sun, D.M., Liang, Y. and Wang, Y.W. (2012) The Status Quo and Prospects of Green Building Development in Mainland China. Building Science, 28, $1-7+68$. 